\title{
Comparative analysis of two FFQ
}

\author{
Jennifer B Keogh ${ }^{1, *}$, Kylie Lange ${ }^{2}$ and Julie Syrette ${ }^{1}$ \\ ${ }^{1}$ CSIRO Human Nutrition, PO Box 10041 BC, Adelaide, SA 5000, Australia: ${ }^{2}$ Department of Medicine, Centre \\ of Clinical Research Excellence in Nutritional Physiology, Interventions and Outcomes, University of Adelaide, \\ Adelaide, South Australia
}

Submitted 13 January 2009: Accepted 4 January 2010: First published online 1 March 2010

\begin{abstract}
Objective: To examine the utility of a shorter FFQ compared with a longer FFQ, both of which are commonly used in Australia.

Design: Comparative study.

Setting: Community setting.

Subjects: One hundred and fifty-nine men (mean 55 ( АЕм 7) years) screened for participation in an intervention study completed both the Commonwealth Scientific and Industrial Research Organisation FFQ and the Cancer Council of Victoria FFQ. Agreement between both questionnaires was assessed according to Bland-Altman plots and limits of agreement (LOA) and ordinary least products regression to test for the presence of fixed and proportional bias.

Results: There was good relative agreement between the methods for energy and macronutrients (Pearson's correlation coefficients: energy $r=0 \cdot 7$, protein $r=0 \cdot 6$, fat $r=0 \cdot 8$, carbohydrate $r=0 \cdot 7$, alcohol $r=0 \cdot 8 ; P<0 \cdot 01$ ). Mean group-level agreement for the majority of nutrients (70\%) fell between $80 \%$ and $110 \%$. According to the criteria used (maximum LOA was 50-200\% and no significant proportional bias), there was acceptable agreement between the FFQ for energy and total saturated and monounsaturated fat, but not for protein, carbohydrate and fibre. Micronutrients that did not meet the agreement criteria including calcium, iron, thiamin, niacin, riboflavin and folate. When the data were analysed according to quintiles, the majority of subjects were either in exactly the same quintile or within one quintile for most nutrients, and 1-2\% were grossly misclassified by three or four quintiles.

Conclusions: We conclude that there is sufficient agreement between the instruments for group-level comparisons in men, but they are not interchangeable for estimation of individual intakes.
\end{abstract}

FFQ are widely used to assess dietary intake ${ }^{(1,2)}$. They are relatively low cost, are easy to administer and can assess dietary intake over a long period of time ${ }^{(3)}$. In Australia, there are two FFQ that are frequently used to assess dietary intake: the Commonwealth Scientific and Industrial Research Organisation (CSIRO) FFQ and the Cancer Council of Victoria (CCV) FFQ ${ }^{(4,5)}$. The characteristics of each instrument are different. The CCV FFQ is a seventyfour-item self-administered FFQ, which is optically scannable to provide an analysis of dietary intake. It is quick and easy to use and has been validated in relation to $7 \mathrm{~d}$ weighed food records in premenopausal women. However, it is thought to underestimate carbohydrate intake; it has a truncated upper range of frequency categories and does not include some common foods ${ }^{(6)}$. The CSIRO FFQ contains 200 items, has serving sizes that can be altered by the respondent and can be modified, i.e. extra questions can be added according to the particular focus of the study. However, it is a booklet that takes $45 \mathrm{~min}$ to complete and has to be manually coded before the manual data entry, increasing both the respondent burden and the resources required to analyse the FFQ. The CSIRO FFQ had been validated by ourselves and others ${ }^{(7-10)}$.

The objectives of the present study were to examine the utility of the shorter FFQ compared with the longer FFQ and to establish the agreement between the CSIRO FFQ and the CCV FFQ, as there are advantages of reduced respondent burden and fewer professional resources of using a machine-readable FFQ.

\section{Methods}

\section{Subjects}

The subjects in the present study were men ( $n$ 159) who had volunteered to be screened for a dietary intervention study to establish the bioavailability and bioefficacy in humans of selenium supplied in high-selenium wheat. 
The inclusion criteria were healthy men aged $40-70$ years, not supplementing with selenium or other vitamins and antioxidants. Exclusion criteria were sensitivity to study foods, i.e. gluten/wheat intolerance, or unable to comprehend or comply with the study protocol. The protocol was approved by the CSIRO Human Nutrition Human Research Ethics Committee and all subjects gave written informed consent.

\section{FFQ}

The CSIRO FFQ is a quantified FFQ containing a list of 200 items of food and drink. As a guide to serving size estimates, each food has a designated 'standard' serving or portion size described in household measures and/or by weight and volume alongside. This could be changed where necessary by the respondent. Respondents were asked to indicate how often they ate each of these foods using an open-ended alpha-numeric scale ( $\mathrm{N}$ for never; $\mathrm{R}$ for rarely; 1, 2, 3, etc. per $\mathrm{D}, \mathrm{W}$ and $\mathrm{M}$ for once, twice, three times, etc. per day, week and month, respectively). There was a series of qualitative questions related to food preparation and cooking techniques, the use of salt or sugar in beverages, types of milk or breads and types of fats used as spreads or in cooking. The answers to those questions were used where necessary to modify the nutrient profile of the foods in the main frequency list. Information on other commonly eaten foods, not in the main list, was also sought and included in the analysis. The responses were analysed for usual daily nutrient intake and grams consumed at CSIRO (Adelaide, South Australia) using a modification of the FREQUAN dietary analysis programme ${ }^{(4)}$. Nutrient composition was derived from the four sources: the Australian nutrient database (NUTTAB) ${ }^{(11)}$, the British Food Composition Tables ${ }^{(12)}$, the US Department of Agriculture (USDA) food tables ${ }^{(13)}$ and the manufacturers' data. The range of nutrients that can be obtained from the CSIRO FFQ is greater than the CCV FFQ and can include, for example, selenium, vitamin $\mathrm{B}_{12}$, pantothenic acid, biotin, vitamin $\mathrm{B}_{6}$ and fatty acids. The CCV FFQ had been validated in a number of studies ${ }^{(7-10)}$.

The CCV FFQ is a seventy-four-item semi-quantitative machine-scannable FFQ that has been described in detail elsewhere $^{(14)}$. In short, the first page of the four-page FFQ includes questions on how many pieces of fresh fruit and how many types of vegetables are consumed daily. Other questions are about the amount and type of milk and bread eaten, type of spread used, amount of sugar consumed daily, weekly egg intake and type of cheese eaten. The second page of the FFQ consists of four sets of photos depicting serving sizes; pages three and four of the CCV FFQ are a list of seventy-four items with frequency options ranging from never to three or more times per day, and more detailed information about alcohol.

The food composition data used to calculate nutrients are from NUTTAB95 ${ }^{(11)}$, supplemented by other data where necessary $(12,15,16,17)$. The output includes water, kilojoules, fat (total), protein, carbohydrate (total), sugar, starch and dextrins, dietary fibre, cholesterol, sodium, potassium, calcium, phosphorus, magnesium, iron, zinc, retinol equivalent, retinol, thiamin, $\beta$-carotene equivalents, riboflavin, niacin, niacin equivalents, vitamin $\mathrm{C}$, alcohol, SFA (total), MUFA (total) and PUFA (total). Following the present study, the CCV extended the calculations to include individual fatty acids, carotenoids, glycaemic index and glycaemic load. The FFQ and participant barcodes were obtained from the CCV, and the completed FFQ were returned to the CCV for analysis using the software based on the NUTTAB95 food composition database.

The recall period for both FFQ was usual intake defined as during the past year.

\section{Administration of the $F F Q$}

Both the CCV FFQ and the CSIRO FFQ were completed on one occasion in the CSIRO research unit when the volunteers attended for the screening visit for the intervention trial. They were given clear instructions to recall their usual dietary intake over the past year. The questionnaires were not completed in a specified order.

\section{Statistical analysis}

Statistical analysis was performed using the Statistical Package for the Social Sciences statistical software package version $16 \cdot 0$ for Windows ${ }^{\mathrm{TM}}$ (2008, SPSS Inc., Chicago, IL, USA). In comparison with earlier studies, Pearson correlation coefficients and paired $t$ tests were used to compare the questionnaires; however, the limited usefulness of these methods is acknowledged. Agreement between both questionnaires was assessed according to the Bland-Altman plots and limits of agreement (LOA) ${ }^{(18)}$ and ordinary least products regression to test for the presence of fixed and proportional bias ${ }^{(19)}$. Proportional bias exists when there is a relationship between the extent of agreement and the level of intake. Anti-logging the Bland-Altman mean agreement and LOA resulted in values being reported as CCV FFQ intake as a percentage of CSIRO FFQ intake. Exact agreement between both questionnaires was indicated by $100 \%$ mean agreement. The criteria for agreement were defined as maximum LOA of 50-200\%, and there was no significant proportional bias. The agreement between the relative rankings of the questionnaires was assessed by classifying subjects into quintiles and cross-tabulating. Weighted $\kappa$ statistics were also calculated for the strength of agreement. Data are presented as means and sEm unless otherwise stated. All intake data were log transformed before the analysis and statistical significance was determined by $P<0 \cdot 05$.

\section{Results}

One hundred and fifty-nine men aged 55 (sЕм 0.5) years, with a BMI of $27 \cdot 4(\operatorname{sem~} 0 \cdot 3) \mathrm{kg} / \mathrm{m}^{2}$ completed both FFQ. 
Table 1 Agreement between the CSIRO FFQ and the CCV FFQ according to Bland-Altman limits of agreement ${ }^{(18)}$ (LOA) and ordinary least products regression ${ }^{(19)}$

\begin{tabular}{|c|c|c|c|c|c|c|c|c|c|c|}
\hline & \multicolumn{2}{|c|}{ CSIRO FFQ } & \multicolumn{2}{|c|}{ CCV FFQ } & \multirow{2}{*}{$\begin{array}{c}\text { Correlation } \\
r^{\star}\end{array}$} & \multirow{2}{*}{$\begin{array}{c}\text { Mean \% } \\
\text { agreementt }\end{array}$} & \multirow{2}{*}{$\begin{array}{l}95 \% \\
\text { LOA } \ddagger\end{array}$} & \multirow[b]{2}{*}{$\beta \S$} & \multirow{2}{*}{$\begin{array}{l}\text { Fixed } \\
\text { biasll }\end{array}$} & \multirow{2}{*}{$\begin{array}{l}\text { Proportional } \\
\text { bias }\end{array}$} \\
\hline & Mean & SEM & Mean & SEM & & & & & & \\
\hline Energy (kJ) & 10578 & 245 & 9910 & 273 & 0.689 & 93 & 57,151 & 0.13 & No & No \\
\hline Protein (g) & $105 \cdot 6$ & $2 \cdot 6$ & $106 \cdot 9$ & $3 \cdot 4$ & 0.692 & 101 & 59,171 & -0.15 & Yes & Yes \\
\hline Fat $(g)$ & $92 \cdot 6$ & $2 \cdot 7$ & $90 \cdot 4$ & $3 \cdot 0$ & 0.748 & 97 & 56,166 & 0.09 & No & No \\
\hline Carbohydrate (g) & $296 \cdot 3$ & $7 \cdot 2$ & $250 \cdot 8$ & $7 \cdot 3$ & 0.633 & 84 & 48,147 & 0.11 & Yes & No \\
\hline Fibre (g) & $31 \cdot 3$ & 0.9 & $27 \cdot 7$ & 0.9 & 0.622 & 87 & 45,171 & 0.11 & Yes & No \\
\hline Calcium (g) & $1140 \cdot 1$ & $38 \cdot 6$ & $981 \cdot 6$ & $25 \cdot 7$ & 0.677 & 89 & 48,167 & -0.35 & Yes & Yes \\
\hline Sugar $(\mathrm{g})$ & $159 \cdot 9$ & $4 \cdot 8$ & $110 \cdot 0$ & $3 \cdot 7$ & 0.643 & 69 & 35,135 & -0.06 & No & No \\
\hline Starch (g) & $134 \cdot 2$ & $3 \cdot 6$ & $139 \cdot 4$ & $4 \cdot 5$ & 0.643 & 102 & 54,193 & $0 \cdot 16$ & Yes & Yes \\
\hline Sodium (mg) & $3711 \cdot 6$ & $105 \cdot 8$ & $3060 \cdot 4$ & $98 \cdot 7$ & 0.675 & 81 & 45,146 & $0 \cdot 10$ & Yes & No \\
\hline Potassium (mg) & $4498 \cdot 5$ & $102 \cdot 7$ & $3425 \cdot 4$ & $89 \cdot 2$ & 0.598 & 76 & 44,131 & 0.05 & No & No \\
\hline Magnesium (mg) & $413 \cdot 6$ & $9 \cdot 7$ & $380 \cdot 5$ & $11 \cdot 0$ & 0.619 & 91 & 51,160 & 0.14 & Yes & Yes \\
\hline Phosphorus (mg) & $1747 \cdot 6$ & $44 \cdot 2$ & $2185 \cdot 9$ & $80 \cdot 5$ & 0.512 & 121 & 57,253 & 0.29 & Yes & Yes \\
\hline Iron (mg) & $16 \cdot 7$ & 0.5 & $16 \cdot 5$ & 0.6 & 0.613 & 96 & 49,187 & 0.22 & Yes & Yes \\
\hline Zinc (mg) & $13 \cdot 7$ & 0.4 & $13 \cdot 6$ & 0.4 & 0.682 & 99 & 56,174 & 0.07 & No & No \\
\hline Retinol $(\mu \mathrm{g})$ & $893 \cdot 7$ & $125 \cdot 5$ & $389 \cdot 5$ & $13 \cdot 0$ & 0.297 & 63 & 12,330 & -0.72 & Yes & Yes \\
\hline$\beta$-Carotene $(\mu \mathrm{g})$ & $4783 \cdot 3$ & $168 \cdot 6$ & $2939 \cdot 8$ & $100 \cdot 0$ & 0.527 & 62 & 25,151 & -0.04 & No & No \\
\hline Thiamin (mg) & $2 \cdot 0$ & 0.1 & 1.9 & $0 \cdot 1$ & 0.659 & 94 & 49,178 & $0 \cdot 13$ & Yes & Yes \\
\hline Riboflavin (mg) & $2 \cdot 6$ & $0 \cdot 1$ & $2 \cdot 8$ & 0.1 & 0.668 & 105 & 54,201 & 0.09 & No & No \\
\hline Niacin (mg) & $24 \cdot 1$ & 0.6 & $28 \cdot 2$ & $1 \cdot 0$ & 0.656 & 113 & 59,216 & 0.29 & Yes & Yes \\
\hline Vitamin C (mg) & $196 \cdot 8$ & $9 \cdot 6$ & $158 \cdot 4$ & $7 \cdot 6$ & 0.672 & 82 & 33,202 & -0.11 & No & No \\
\hline Vitamin $E(\mu g)$ & $10 \cdot 2$ & 0.3 & $8 \cdot 1$ & 0.3 & 0.578 & 81 & 36,182 & -0.20 & No & No \\
\hline Folate $(\mu \mathrm{g})$ & $285 \cdot 8$ & $8 \cdot 3$ & $341 \cdot 3$ & $10 \cdot 6$ & 0.552 & 119 & 59,240 & 0.03 & No & No \\
\hline Alcohol (g) & $14 \cdot 1$ & $1 \cdot 3$ & $22 \cdot 1$ & $1 \cdot 7$ & 0.902 & 156 & 38,644 & 0.05 & Yes & No \\
\hline Cholesterol (mg) & $311 \cdot 8$ & $12 \cdot 0$ & $320 \cdot 4$ & $12 \cdot 8$ & 0.771 & 103 & 55,190 & -0.02 & No & No \\
\hline SFA $(g)$ & $37 \cdot 5$ & $1 \cdot 3$ & $35 \cdot 1$ & $1 \cdot 2$ & 0.773 & 94 & 53,167 & -0.01 & No & No \\
\hline MUFA (g) & $33 \cdot 2$ & $1 \cdot 0$ & $32 \cdot 6$ & $1 \cdot 1$ & 0.724 & 97 & 53,176 & $0 \cdot 12$ & No & No \\
\hline PUFA (g) & $15 \cdot \overline{5}$ & 0.5 & $14 \cdot 8$ & 0.5 & 0.678 & 94 & 45,199 & 0.05 & No & No \\
\hline$\%$ Energy as protein & $17 \cdot 0$ & 0.2 & $18 \cdot 1$ & 0.2 & 0.531 & 106 & 80,142 & 0.06 & No & No \\
\hline $\begin{array}{l}\% \text { Energy as } \\
\text { carbohydrate }\end{array}$ & $44 \cdot 9$ & $0 \cdot 4$ & $42 \cdot 7$ & 0.5 & 0.665 & 95 & 75,119 & $0 \cdot 17$ & Yes & Yes \\
\hline$\%$ Energy as fat & $32 \cdot 0$ & 0.4 & $34 \cdot 1$ & 0.4 & $0 \cdot 711$ & 107 & 83,137 & 0.03 & No & No \\
\hline$\%$ Energy as alcohol & $4 \cdot 1$ & 0.4 & $6 \cdot 7$ & 0.5 & $0 \cdot 883$ & 165 & 44,617 & 0.08 & Yes & Yes \\
\hline$\%$ Energy as sugar & $24 \cdot 2$ & 0.5 & $18 \cdot 7$ & 0.4 & 0.702 & 77 & 49,120 & $0 \cdot 11$ & Yes & No \\
\hline$\%$ Energy as starch & $20 \cdot 4$ & 0.3 & $23 \cdot 0$ & 0.4 & 0.587 & 113 & 76,168 & 0.04 & No & No \\
\hline$\%$ Energy as PUFA & $5 \cdot 4$ & $0 \cdot 1$ & $5 \cdot 6$ & $0 \cdot 1$ & 0.611 & 104 & 59,183 & 0.00 & No & No \\
\hline$\%$ Energy as MUFA & $11 \cdot 5$ & 0.2 & $12 \cdot 2$ & 0.2 & 0.664 & 107 & 78,146 & -0.04 & No & No \\
\hline$\%$ Energy as SFA & $12 \cdot 9$ & 0.3 & $13 \cdot 2$ & 0.2 & 0.755 & 103 & 73,146 & -0.11 & Yes & Yes \\
\hline
\end{tabular}

${ }^{*}$ Pearson correlation coefficient; $P<0.001$ for all nutrients.

tExpressed as (mean (CSIRO FFQ - CCV FFQ)) as a percentage of CSIRO FFQ.

$\$ 95 \% \mathrm{LOA}=$ mean difference \pm 2 (sD differences).

§Slope from linear regression of the mean of the methods against the difference between methods.

IISignificant fixed bias if $95 \% \mathrm{Cl}$ of the intercept from least products regression of CSIRO FFQ on CCV FFQ contains 0 .

-Significant proportional bias if $95 \% \mathrm{Cl}$ of the slope from least products regression of CSIRO FFQ on CCV FFQ contains 1 .

As this was a comparison between two similar methods, it was considered valid to include all responses in the analysis regardless of energy intake.

Pearson's correlation coefficients were highly statistically significant (all $P<0 \cdot 001$ ) and for the majority of nutrients ranged from $r=0.512$ to $r=0.883$ except for retinol for which $r=0 \cdot 297$. Agreement between both questionnaires, according to the Bland and Altman LOA $^{(18)}$ and ordinary least products regression ${ }^{(19)}$ are shown in Table 1.

There is significant evidence of a fixed bias for protein, carbohydrate, fibre and calcium with 3-16\% lower values for the CCV FFQ, with the exception of protein for which the CCV FFQ averaged 1\% higher. Protein and calcium also exhibited significant proportional bias. At low calcium intakes, the CCV FFQ reported higher intakes than the CSIRO FFQ and the opposite was true at high calcium intakes. The opposite was true for protein, i.e. at low protein intakes the CCV FFQ reported lower intakes than the CSIRO FFQ and at high protein intakes the CSIRO FFQ reported lower intakes than the CCV FFQ.

The cumulative percentage agreement between the quintiles of nutrient intakes derived from both questionnaires is shown in Table 2. When the data were analysed according to quintiles, approximately $80 \%$ of subjects were either in exactly the same quintile or within one quintile for most nutrients, agreement was 69-74\% for six of the nutrients and 1-2\% were grossly misclassified by three or four quintiles.

\section{Discussion}

The finding that the CCV FFQ reported lower carbohydrate was in agreement with our previous findings ${ }^{(6)}$. The underestimation of carbohydrate suggests that some 
Table 2 Quintiles cumulative percentage agreement between nutrient intakes derived from the CSIRO FFQ and the CCV FFQ

\begin{tabular}{|c|c|c|c|c|}
\hline & \multicolumn{2}{|c|}{$\%$ Agreement } & \multirow[b]{2}{*}{$\%$ Gross misclassification* } & \multirow[b]{2}{*}{ Weighted $\kappa$} \\
\hline & Exact & \pm One-fifth & & \\
\hline Energy (kJ) & 36 & 80 & $3 \cdot 8$ & 0.64 \\
\hline Protein $(\mathrm{g})$ & 45 & 79 & $5 \cdot 0$ & 0.63 \\
\hline Fat $(\mathrm{g})$ & 46 & 81 & $3 \cdot 8$ & 0.67 \\
\hline Carbohydrate (g) & 31 & 77 & $5 \cdot 0$ & 0.58 \\
\hline Fibre (g) & 38 & 79 & $8 \cdot 8$ & 0.57 \\
\hline Calcium (mg) & 35 & 79 & $5 \cdot 7$ & $0 \cdot 61$ \\
\hline Sugar (total g) & 37 & 75 & $3 \cdot 8$ & $0 \cdot 60$ \\
\hline Starch (g) & 38 & 74 & $4 \cdot 4$ & 0.58 \\
\hline Sodium (mg) & 43 & 75 & $6 \cdot 3$ & 0.58 \\
\hline Potassium (mg) & 38 & 72 & $5 \cdot 7$ & 0.55 \\
\hline Magnesium (mg) & 38 & 72 & $3 \cdot 8$ & 0.56 \\
\hline Phosphorus (mg) & 34 & 75 & $8 \cdot 8$ & 0.51 \\
\hline Iron (mg) & 38 & 79 & $7 \cdot 5$ & 0.58 \\
\hline Zinc (mg) & 38 & 78 & $5 \cdot 7$ & 0.61 \\
\hline Retinol $(\mu \mathrm{g})$ & 33 & 69 & $9 \cdot 4$ & $0 \cdot 41$ \\
\hline$\beta$-Carotene $(\mu \mathrm{g})$ & 26 & 72 & $11 \cdot 9$ & 0.42 \\
\hline Thiamin (mg) & 37 & 77 & $5 \cdot 0$ & 0.58 \\
\hline Riboflavin (mg) & 45 & 79 & $3 \cdot 8$ & 0.66 \\
\hline Niacin (mg) & 36 & 83 & $8 \cdot 2$ & 0.61 \\
\hline Vitamin C (mg) & 41 & 87 & $1 \cdot 9$ & $0 \cdot 72$ \\
\hline Vitamin $E(\mu \mathrm{g})$ & 38 & 71 & $8 \cdot 2$ & 0.52 \\
\hline Folate $(\mu \mathrm{g})$ & 36 & 76 & $6 \cdot 3$ & 0.55 \\
\hline Alcohol (g) & 52 & 89 & $1 \cdot 3$ & 0.78 \\
\hline Cholesterol (mg) & 42 & 85 & $1 \cdot 3$ & $0 \cdot 72$ \\
\hline SFA (g) & 43 & 86 & $2 \cdot 5$ & $0 \cdot 72$ \\
\hline MUFA (g) & 45 & 80 & $5 \cdot 7$ & 0.63 \\
\hline PUFA (g) & 43 & 81 & $4 \cdot 4$ & 0.65 \\
\hline$\%$ Energy as protein & 39 & 74 & $5 \cdot 7$ & 0.56 \\
\hline$\%$ Energy as carbohydrate & 43 & 79 & $6 \cdot 3$ & 0.62 \\
\hline$\%$ Energy as fat & 42 & 77 & $5 \cdot 0$ & 0.62 \\
\hline \% Energy as alcohol & 48 & 90 & $2 \cdot 5$ & $0 \cdot 76$ \\
\hline$\%$ Energy as sugar & 37 & 79 & $5 \cdot 7$ & 0.62 \\
\hline$\%$ Energy as starch & 33 & 75 & $6 \cdot 9$ & 0.55 \\
\hline$\%$ Energy as PUFA & 36 & 78 & $5 \cdot 7$ & 0.59 \\
\hline$\%$ Energy as MUFA & 47 & 81 & $8 \cdot 2$ & 0.58 \\
\hline$\%$ Energy as SFA & 45 & 86 & $2 \cdot 5$ & 0.43 \\
\hline
\end{tabular}

${ }^{*}$ Gross misclassification $=$ disagreement by three or four quintiles.

key foods, e.g. soft drinks, are missing from this FFQ. However, as fibre also appears to be underestimated, it appears that other carbohydrate-containing foods, e.g. wholemeal bread and fibre-containing cereals, may also be underestimated.

The differences in calcium intake between both questionnaires are more difficult to explain, especially as there is proportional as well as fixed bias such that at low calcium intakes the CCV FFQ reports higher intakes than the CSIRO FFQ, and the opposite is true at high calcium intakes.

FFQ are often used in epidemiological studies and have been shown to perform well in comparison with other dietary intake methods, e.g. a $7 \mathrm{~d}$ diet diary, dietary history and biochemical markers and repeated $24 \mathrm{~h}$ diet recalls ${ }^{(20-22)}$. A longer version of the CSIRO FFQ was used in an Australian study that linked consumption of trans fatty acids with an increased risk of coronary artery disease $^{(23)}$. The CCV FFQ has helped to establish that fruit and vegetable intakes are inversely associated with CVD mortality ${ }^{(24)}$. An FFQ is being used in the analysis of risk from the diet in relation to cancer incidence in the large
European Prospective Investigation into Cancer and Nutrition (EPIC) Study, as it is considered that measurement error will be overcome by the large dietary heterogeneity ${ }^{(25)}$. This FFQ has been validated against ten $24 \mathrm{~h}$ recalls and found to have an estimated level of validity similar to other FFQ measurements ${ }^{(26)}$. However, in the UK EPIC study, dietary data are collected using a $7 \mathrm{~d}$ diary, as correlations between dietary intake and urinary excretion of nitrogen and potassium were low ${ }^{(25)}$.

Day et $a l^{(27)}$ compared urinary nitrogen, potassium and sodium with intakes from an FFQ and a $7 \mathrm{~d}$ diet diary. They found that the bias within the FFQ was much greater than the $7 \mathrm{~d}$ diet diary and was greater than that would be deduced if validation studies were based solely on another diet methodology. We have published data showing that protein intake derived from the CSIRO FFQ was correlated significantly with urinary urea and sodium, but not with potassium ${ }^{(8)}$.

Despite their limitations, FFQ continue to be used in large studies such as the Health Professionals' Follow-up Study, the Nurses' Health Study and the Physicians' Health 
Study ${ }^{(28-30)}$. A 124-item food frequency has been used to evaluate the relationship between red meat intake and breast cancer ${ }^{(29)}$. A relative risk of 1.36 could be shown when women in the lowest quintile of red meat intake during adolescence were compared with women in the highest quintile. A shortened FFQ was used to examine the association between fish and $n-3$ fatty acid intake and colorectal cancer risk ${ }^{(30)}$. In the present study, a relative risk of 0.60 was shown for the highest $v$. the lowest category of fish intake. Thus, despite their imprecision, FFQ are capable of demonstrating the diet-disease relationships. Both the CSIRO FFQ and the CCV FFQ have been used in a similar way to investigate the diet-disease relationships in adults and children, respectively ${ }^{(31,32)}$.

It is recommended in validation studies that the test measure should be administered before the assessment of the reference measure ${ }^{(2)}$. However, in the present study, the two FFQ were being compared to one another and we believed that it was not necessary to follow this sequence.

We conclude that while both questionnaires rank the majority of subjects in either exactly the same quintile or within one quintile for all nutrients, they are not interchangeable for estimation of individual dietary intakes. However, the study was only in men and the conclusions cannot be generalised to women.

There is a continuing concern that the CCV FFQ appears to underestimate carbohydrate intake and this needs to be taken into account if this methodology is being used. The larger range of nutrients and greater flexibility of the CSIRO FFQ make it a useful instrument.

\section{Acknowledgements}

There are no conflicts of interest. The study was partly funded by the National Centre of Excellence for Functional Foods, Australia. J.B.K. designed the study, contributed to the data analysis and interpretation and wrote the manuscript; K.L. provided expert advice on statistical analysis and undertook some of the data analysis; J.S. assisted with the design of the study and contributed to the data analysis. The authors acknowledge the CSIRO Clinical Research Staff for their assistance with the present study.

\section{References}

1. Thompson FE, Moler JE, Freedman LS et al. (1997) Register of dietary assessment calibration-validation studies: a status report. Am J Clin Nutr 65, 1142S-1147S.

2. Cade J, Thompson R, Burley V et al. (2002) Development, validation and utilisation of food-frequency questionnaires - a review. Public Health Nutr 5, 567-587.

3. Nelson M \& Bingham S (1997) Assessment of food consumption and nutrient intake. In Design Concepts in Nutritional Epidemiology, pp. 123-169 [BM Margetts, editor]. Oxford: Oxford University Press.
4. Baghurst KI \& Record SJ (1984) A computerised dietary analysis system for use with diet diaries or food frequency questionnaires. Community Health Stud 8, 11-18.

5. Ireland P, Jolley D, Giles G et al. (1994) Development of the Melbourne FFQ: a food frequency questionnaire for use in an Australian prospective study involving an ethnically diverse cohort. Asia Pacific J Clin Nutr 3, 19-31.

6. Xinying PX, Noakes M \& Keogh J (2004) Can a food frequency questionnaire be used to capture dietary intake data in a 4 week clinical intervention trial? Asia Pac J Clin Nutr 13, 318-323.

7. Rohan RE, Record SJ \& Cook MJ (1987) Repeatability of estimates of nutrient and energy intake: the quantitative food frequency approach. Nutr Res 7, 125-137.

8. Lassale C, Guilbert C, Keogh J et al. (2009) Estimating food intakes in Australia: validation of the CSIRO food frequency questionnaire (C-FFQ) against weighed dietary intakes. I Num Nutr Diet 22, 559-566.

9. Ambrosini GL, de Klerk NH, O'Sullivan TA et al. (2009) The reliability of a food frequency questionnaire for use among adolescents. Eur J Clin Nutr 63, 1251-1259.

10. Ambrosini GL, Mackerras D, de Klerk NH et al. (2003) Comparison of an Australian food-frequency questionnaire with diet records: implications for nutrition surveillance. Public Health Nutr 6, 415-422.

11. Lewis J, Milligan G \& Hunt A (1995) NUTTAB95 Nutrient Data Table for Use in Australia. Canberra: Australian Government Publishing Service.

12. Paul A \& Southgate D (1978) McCance and Widdowson's 'The Composition of Foods'. Amsterdam: Elsevier.

13. US Department of Agriculture, Agricultural Research Service (2010) Nutrient Data Laboratory Home Page. http://www.ars.usda.gov/main/site_main.htm?modecode=1235-45-00 (accessed February 2010).

14. Hodge A, Patterson AJ, Brown WJ et al. (2000) The Anti Cancer Council of Victoria FFQ: relative validity of nutrient intakes compared with weighed food records in young to middle-aged women in a study of iron supplementation. Aust N Z J Public Health 24, 576-583.

15. US Department of Agriculture, Agricultural Research Service (1998) USDA-NCC Carotenoid Database for US Foods - 1998. http://www.nal.usda.gov/fnic/foodcomp/ Data/car98/car98.html (accessed February 2010).

16. Foster-Powell K, Holt $\mathrm{H} \&$ Brand-Miller J (2002) International tables of glycemic index and glycemic load values: 2002. Am J Clin Nutr 76, 5-56

17. Xyris Software (2001) Fatty Acid Compositional Database. http://www.xyris.com.au/fatty_acids/default.htm (accessed February 2010)

18. Bland JM \& Altman DG (1986) Statistical methods for assessing agreement between two methods of clinical measurement. Lancet 1, 307-310.

19. Ludbrook J (2002) Statistical techniques for comparing measurers and methods of measurement: a critical review. Clin Exp Pharmacol Physiol 29, 527-536.

20. Brunner E, Stallone D, Juneja M et al. (2001) Dietary assessment in Whitehall II: comparison of $7 \mathrm{~d}$ diet diary and food-frequency questionnaire and validity against biomarkers. BrJ Nutr 86, 405-414.

21. Katsouyanni K, Rimm EB, Gnardellis C et al. (1997) Reproducibility and relative validity of an extensive semiquantitative food frequency questionnaire using dietary records and biochemical markers among Greek schoolteachers. Int J Epidemiol 26, Suppl. 1, S118-S127.

22. Bohlscheid-Thomas S, Hoting I, Boeing $\mathrm{H}$ et al. (1997) Reproducibility and relative validity of energy and macronutrient intake of a food frequency questionnaire developed for the German part of the EPIC project. European Prospective Investigation into Cancer and Nutrition. Int $J$ Epidemiol 26, Suppl. 1, S71-S81. 
23. Clifton PM, Keogh JB \& Noakes M (2004) Trans fatty acids in adipose tissue and the food supply are associated with myocardial infarction. $J$ Nutr 134, 874-879.

24. Harriss LR, English DR, Powles J et al. (2007) Dietary patterns and cardiovascular mortality in the Melbourne Collaborative Cohort Study. Am J Clin Nutr 86, 221-229.

25. Bingham SA, Welch AA, McTaggart A et al. (2001) Nutritional methods in the European Prospective Investigation of Cancer in Norfolk. Public Health Nutr $\mathbf{4}$, 847-858.

26. Johansson I, Hallmans G, Wikman A et al. (2002) Validation and calibration of food-frequency questionnaire measurements in the Northern Sweden Health and Disease cohort. Public Health Nutr 5, 487-496.

27. Day N, McKeown N, Wong M et al. (2001) Epidemiological assessment of diet: a comparison of a 7-day diary with a food frequency questionnaire using urinary markers of nitrogen, potassium and sodium. Int J Epidemiol 30, 309-317.
28. Willett W, Stampfer M, Chu NF et al. (2001) Assessment of questionnaire validity for measuring total fat intake using plasma lipid levels as criteria. Am J Epidemiol 154, 1107-1112.

29. Linos E, Willett WC, Cho E et al. (2008) Red meat consumption during adolescence among premenopausal women and risk of breast cancer. Cancer Epidemiol Biomarkers Prev 17, 2146-2151.

30. Hall MN, Chavarro JE, Lee IM et al. (2008) A 22-year prospective study of fish, n-3 fatty acid intake, and colorectal cancer risk in men. Cancer Epidemiol Biomarkers Prev 17, 1136-1143.

31. Giles GG, Simpson JA, English DR et al. (2006) Dietary carbohydrate, fibre, glycaemic index, glycaemic load and the risk of postmenopausal breast cancer. Int J Cancer $\mathbf{1 1 8}$, 1843-1847.

32. Almqvist C, Garden F, Xuan W et al. (2007) Omega-3 and omega-6 fatty acid exposure from early life does not affect atopy and asthma at age 5 years. J Allergy Clin Immunol 119, 1438-1444. 